\title{
BIẾN ĐộNG CUNG CẦU LƯƠNG THỰC THỤ̉C PHẨM TRONG BỐI CẢNH COVID-19
}

\author{
Nguyễn Thị Thu Hà, Hà Thị Hồng Hạnh, Hà Minh Hằng, Dương Minh Hằng, \\ Nguyễn Thị Hằng, Nguyễn Khánh Toàn
}

Đại học Quốc gia Hà Nội

Ngày 25 Tháng 1 năm 2022

Preprint DOI: https://osf.io/s4gh9

\section{Bối cảnh}

Trong bối cảnh đại dịch COVID-19 tiếp tục diễn biến phức tạp, các nước trên thế giới đều ra sức bảo vệ nguồn lương thực thực phẩm của mình bằng các chiến lược khác nhau. Nước xuất khẩu thì điều chỉnh chính sách xuất khẩu, "găm hàng”, xuất khẩu ít đi khiến nguồn cung ứng bị gián đoạn, giá cả bấp bênh, trong khi nước nhập khẩu thì cố gắng tích trữ nhiều. Nếu tình trạng kéo dài, một số nước phải đối mặt với nguy cơ an ninh lương thực bị đe dọa, thiếu hụt nguồn cung hàng hóa.

Tổ chức Nông Lương Liên Hợp Quốc (FAO) đã đưa ra cảnh báo về nguy cơ thiếu hụt lương thực trên toàn thế nếu các nước không quản lý tốt tình trạng khủng hoảng do đại dịch COVID 19 gây ra (Lê Dương, 2020). Bên cạnh đó, $\mathrm{FAO}$ cũng bày tỏ sự lo lắng về việc đứt gãy chuỗi cung ứng lương thực toàn cầu và đưa ra nhận định rằng thế giới có thể phải đối mặt với cuộc khủng hoảng lương thực nếu không kịp thời triển khai các biện pháp bảo vệ những đối tượng dễ bị tổn thương và duy trì chuỗi cung ứng thực phẩm toàn cầu dưới tác động của đại dịch. Một thống kê của $\mathrm{FAO}$ cho thấy, có khoảng 820 triệu người (chiếm gần 12\% dân số) đang trong tình thế không 
đủ lương thực, thực phẩm để dùng hàng ngày và khoảng 113 triệu người đang phải sống trong đói nghèo và cần phải nhờ vào trợ cấp lương thực (BBT, 2020).

Ở Việt Nam, dịch bệnh COVID 19 diễn biến phức tạp: hạn chế di chuyển, đóng cửa hàng quán, sự phân phối nguồn hàng không đều giữa các vùng an toàn và không an toàn đã gây áp lực lên thị trường, làm đứt gãy chuỗi cung cầu (La, 2020; Nguyên, 2020). Ở một số tỉnh, thành phố của nước ta xảy ra tình trạng cá nhân và tổ chức đầu cơ tích trữ hàng hóa, lương thực, thực phẩm gây rối loạn thị trường, mất cân bằng giá cả gây ảnh hưởng đến nhu cầu mua hàng của người tiêu dùng. Đồng thời do sức mua tăng đột ngột, nhu cầu cao hơn nguồn cung nên có hiện tượng các hộ kinh doanh tự phát, nhỏ lẻ "hét giá" và nhiều nơi quá tải thậm chí "cháy hàng" cục bộ gây ra tình trạng thiếu hụt lương thực, thực phẩm trong thời gian ngắn. Tất cả những yếu tố đó đã gây ra hiện trạng cung - cầu mất cân đối.

Theo báo cáo gần đây của UNCTAD (Hội nghị Liên Hợp Quốc về Thương mại và Phát triển), đối với các nước phát triển, nền kinh tế thế giới giảm 3,5\% trong năm 2020. Tốc độ tăng trưởng khu vực Đông Nam Á cũng giảm 3,9\%. Việt Nam, quốc gia với mức tăng trưởng 2,9\% trong năm 2020 (Manh Hung, 2021), là một nước vượt trội trong khu vực nhờ việc kiểm soát dịch bệnh kịp thời và hiệu quả. UNCTAD dự báo sản lượng thế giới là sẽ tăng trưởng 5,3\% trong năm nay khi nền kinh tế khôi phục vị thế đã mất vào năm 2020, nhưng sẽ chững lại vào năm 2022. Mặc dù tăng trưởng theo xu thế trên vẫn duy trì trong năm 2021-2022, nhưng kinh tế thế giới vào cuối năm 2022 sẽ chỉ đạt 10 nghìn tỷ USD thấp hơn nhiều so với thực tế đáng lẽ sẽ đạt được nếu không có đại dịch COVID 19. Ngoài ra, sự phục hồi của Đông Nam Á cũng sẽ bị chậm lại bởi đợt bùng phát dịch mới nhất, tăng trưởng sẽ phục hồi và bứt tốc vào năm 2022. Khối lượng thương mại quốc tế giảm 5,6\% vào năm 2020 (Manh Hung, 2021), mức giảm này ít nghiêm trọng hơn so với dự đoán. UNCTAD kỳ vọng mức tăng trưởng thực tế có thể đạt gần 10\% vào năm 2021 .

Một cuộc khảo sát của Nielsen IQ được thực hiện vào tháng 2/2020 tại Việt Nam đã chỉ ra rằng COVID 19 đã khiến cho $45 \%$ người tiêu dùng tăng cường dự trữ thực phẩm ở nhà, con số này nhiều hơn trước, $50 \%$ trong số đó giảm tần suất đến các địa điểm để mua hàng hóa (siêu thị, cửa hàng tạp hóa...) và $25 \%$ số người hạn chế các hoạt động ăn ngoài (BBT, 2021). Những mặt hàng được người Việt tích trữ nhiều nhất bao gồm mì gói (+ 67\%), thực phẩm đông lạnh $(+$ $40 \%)$ và xúc xích tiệt trùng $(+19 \%)(B B T, 2021)$. Các mặt hàng thiết yếu cũng có sự tăng 
trưởng về doanh thu do sự gia tăng trong nhu cầu của người tiêu dùng. Khảo sát của Kantar cũng đã cho thấy, việc đóng cửa trên toàn quốc vào tháng 4 năm 2020, bánh mì đóng gói và sữa hộp tại Hồ Chí Minh tăng lần lượt $112 \%$ và $12 \%$ so với cùng kỳ vào năm ngoái. Ngược lại, đồ uống có cồn và đồ uống có đường giảm tiêu thụ trong quý đầu tiên của năm 2020.

Ở châu Âu, nhu cầu về bánh mì tăng 76\% và rau tăng $52 \%$ trong một tuần khi dịch bệnh được công bố (Abhijit Barman, Rubi Das, 2021), mối quan tâm đối với các mặt hàng có cồn không tăng. Theo báo cáo của Hội đồng Nghiên cứu và Kinh tế Nông nghiệp (CREA) của Ý, trong thời gian cách ly của đại dịch COVID 19, tiêu thụ sản phẩm thực phẩm tăng $29 \%$ đối với trái cây, rau 33\%, các loại đậu 26,5\% và dầu ô liu 21,5\% (Abhijit Barman, Rubi Das, 2021). Ở Mỹ, 70\% khách hàng giảm tần suất mua sắm mặt hàng thực phẩm trực tiếp và ưa chuộng hình thức chợ online trong đại dịch.

\section{Nguyên nhân dẫn đến sự biến động cung cầu}

Thư nhất, việc đóng cửa biên giới, ngừng đường bay, thắt chặt xuất nhập khẩu, giảm tiêu tiêu dùng xuống mức tối thiểu được áp dụng khắp nơi ở nhiều quốc gia khiến chuỗi sản xuất thương mại toàn cầu bị đình trệ khi cả đầu vào, đầu ra của doanh nghiệp đều bị thắt lại dẫn đến giảm số lượng hàng hóa. (Francesca De Nicola , Jonathan Timmis, 2020) (OECD, 2020).

Thứ hai, các chính sách, chỉ thị giãn cách của nhà nước khiến việc vận chuyển hàng hóa gặp nhiều khó khăn, các hàng quán, siêu thị, chợ buộc phải đóng cửa để tránh lây lan dịch bệnh dẫn đến tình trạng cầu tăng cao mà cung không đủ.

Thư $b a$, dịch bệnh diễn biến phức tạp tác động đến tâm lý của người tiêu dùng. Người tiêu dùng có xu hướng mua tích trữ nhiều loại hàng hóa, thực phẩm thiết yếu dẫn đến tình trạng khan hiếm hàng hóa, lượng cung không đủ đáp ứng cho lượng cầu. Thực tế như Thành phố Hồ Chí Minh, do có tin đồn Thành phố sẽ bị phong toả từ ngày 15/7/2021 nên việc cung ứng hàng hoá rất căng thẳng, từ sáng ngày 14/7/2021 người dân đổ xô đến các siêu thị để mua hàng hoá, thực phẩm, nhiều siêu thị phát phiếu hẹn giờ đến mua hàng nhưng mãi tận đến trưa, thậm chí đến chiều vẫn có rất nhiều người không nhận được phiếu hẹn do số người có nhu cầu vào siêu thị quá đông và siêu thị không thể đáp ứng đủ. (FAO, 2020) 
Thư tu, đại dịch khiến sản xuất đứt gãy, doanh nghiệp gặp nhiều khó khăn dẫn đến tình trạng cắt giảm nhân sự, thất nghiệp tăng cao ảnh hưởng đến mức sống, thu nhập của người tiêu cùng cũng là yếu tố khiến lượng cầu biến động.

Thư năm, các ngành kinh tế đặc biệt trong các ngành sản xuất, các ngành thường có sự liên kết, tác động lẫn nhau. Do đó, đại dịch COVID đã gây sức ép cho chuỗi cung ứng toàn cầu, một số ngành sản xuất nguyên liệu cắt giảm nhân công dẫn đến sản lượng đầu ra giảm, đẩy giá nguyên liệu lên cao và các ngành sản xuất sử dụng nguyên liệu ấy buộc phải giảm sản lượng đầu ra.

Thú sáu, COVID-19 đã khiến cho nhiều cá nhân, doanh nghiệp gặp khó khăn, những ngành vận tải (phụ trách vận chuyển hàng hóa, nguyên liệu) đình trệ, gây khó khăn cho sản xuất, ảnh hưởng tới sản lượng đầu ra. Bên cạnh đó, các chi phí như thuê kho hàng cũng tăng cao, khiến các doanh nghiệp phải giảm lượng sản phẩm để tiết kiệm chi phí.

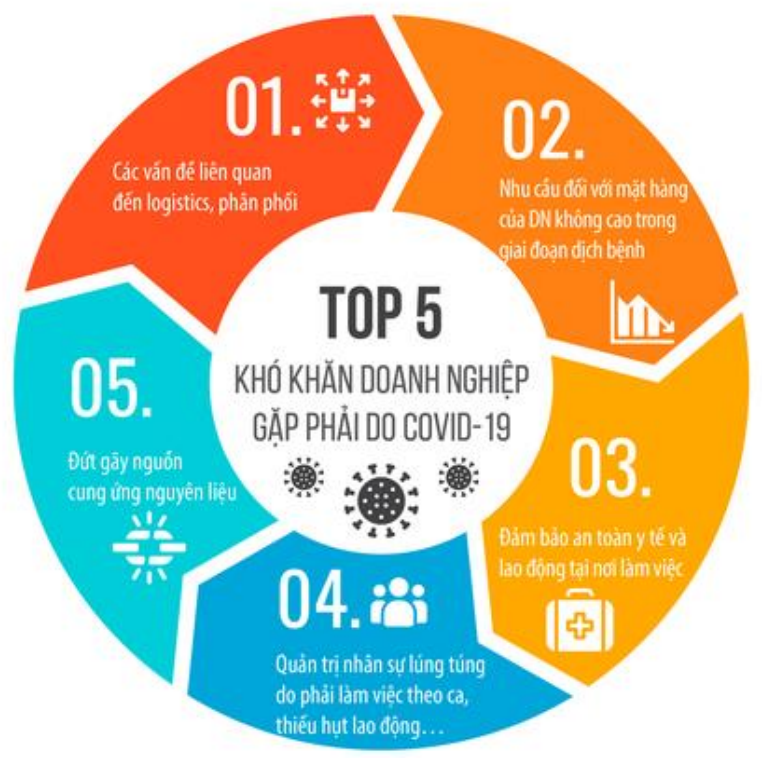

Ảnh 1: Doanh nghiệp gặp nhiều khó khăn ảnh hưởng đến nguồn cung https://vnn-imgs-f.vgcloud.vn/2020/09/23/11/tcbc-top-10-f-b-2020-hinh-3.png 


\section{Giải pháp}

Có rất nhiều cách tiếp cận để đi tìm giải pháp cho vấn đề nêu trên, trong đó nhà nước có thể sử dụng (áp dụng) hệ xử lý thông tin 3D (Khuc, 2022; Vuong, Q.H., 2022). Về cơ bản đây là hệ giải pháp sáng tạo được áp dụng cho nhiều vấn đề từ nhỏ đến lớn. Hệ này gồm có 3 cách thức bao gồm: chuyên gia, hợp tác, và thực thi kỷ luật. Tuy nhiên biện pháp truyền thông được coi là giải pháp rất quan trọng vì liên quan đến thông tin đầu vào cho quá trình nấu luyện và xử lý để tìm ra các giải pháp hiệu quả.

Ở D thứ nhất, các chuyên gia am hiểu trong lĩnh vực cụ thể (cung cầu lương thực thực phẩm) sẽ đưa ra những tư vấn (giải pháp) phù hợp. Ở D thứ hai là sự hợp tác giữa các bên liên quan gồm có nhà nước, doanh nghiệp, chuyên gia, người tiêu dùng để có thông tin thông suốt liên quan. $\mathrm{D}$ thứ ba là tiếp tục duy trì thực thi chính sách kinh tế vĩ mô (cung cầu) và các quy định liên quan với sự giám sát chặt chẽ của các bên nhằm đạt hiệu quả. $\mathrm{Ba} \mathrm{D}$ này được thực hiện đồng thời và không tách rời nhau cho đến khi có được giải pháp tốt nhất được tìm ra (Vuong \& Napier, 2014).

\section{Tài liệu tham khảo}

Abhijit Barman, Rubi Das, P. K. De. (2021). Impact of COVID-19 in food supply chain:

Disruptions and recovery strategy. Mathematics, National Institute of Technology Silchar, Silchar, Assam 788010, India.

https://www.sciencedirect.com/science/article/pii/S2666518221000048

BBT. (2020). Thế giới canh cánh nỗi lo khủng hoảng lương thực vì đại dịch COVID-19. In Đài phát thanh và truyền hình Ninh Bình. https://nbtv.vn/news/4/4174/the-gioi-canh-canh-noilo-khung-hoang-luong-thuc-vi-dai-dich-covid-19

BBT. (2021). Tác động của COVID-19 đến ngành thực phẩm và đồ uống. Innovative Hub Viet Nam. https://innovativehub.com.vn/tac-dong-cua-covid-19-den-nganh-thuc-pham-va-douong-fb/

FAO. (2020). Anticipating the impacts of COVID-19 in humanitarian and food crisis contexts. FAO. https://doi.org/10.4060/ca8464en

Francesca De Nicola , Jonathan Timmis, A. A. (2020). How is COVID-19 transforming global value chains? Lessons from ethiopia and Vietnam. In Worldbank. https://blogs.worldbank.org/voices/how-covid-19-transforming-global-value-chains- 
lessons-ethiopia-and-vietnam

Khuc, Q. Van. (2022). Về khả năng ứng dụng của hệ xử lý thông tin 3D và nguyên lý bán dẫn giá trị trong tìm kiếm giải pháp cho vấn đề ô nhiễm môi trường và biến đổi khí hậu ở Việt Nam. Tạp Chí Kinh Tế và Dụ Báo, 1-5. https://kinhtevadubao.vn/ve-kha-nang-ung-dungcua-he-xu-ly-thong-tin-3d-va-nguyen-ly-ban-dan-gia-tri-trong-tim-kiem-giai-phap-cho-vande-o-nhiem-moi-truong-va-bien-doi-khi-hau-o-viet-nam-20840.html

La, V. P. et al. (2020). Policy response, social media and science journalism for the sustainability of the public health system amid the COVID-19 outbreak: The vietnam lessons. Sustainability (Switzerland), 12(7). https://doi.org/10.3390/su12072931

Lê Dương. (2020). FAO: Thế giới cần hành động để không khủng hoảng lương thực vì COVID19. Báo Bnews.

Manh Hung. (2021). Đại dịch Covid-19 thách thức kinh tế nghiêm trọng với toàn cầu. Báo Điện Tủ - Đảng Cộng Sản Việt Nam. https://dangcongsan.vn/phong-chong-dich-covid-19/undpdai-dich-covid-19-thach-thuc-kinh-te-nghiem-trong-voi-toan-cau-592159.html

Nguyên, A. (2020). Tăng sức cạnh tranh của hàng Việt trong bối cảnh mới. Báo Điện Tư - Đảng Cộng Sản Việt Nam. https://dangcongsan.vn/kinh-te-va-hoi-nhap/tang-suc-canh-tranh-cuahang-viet-trong-boi-canh-moi-567253.html

OECD. (2020). COVID-19 and the food and agriculture sector: Issues and policy responses. OECD. https://www.oecd.org/coronavirus/policy-responses/covid-19-and-the-food-andagriculture-sector-issues-and-policy-responses-a23f764b/

Vuong, Q. H., et al. (2022). Covid-19 vaccines production and societal immunization under the serendipity-mindsponge-3D knowledge management theory and conceptual framework. Humanities and Social Sciences Communications, 9, 22. Retrieved from: https://www.nature.com/articles/s41599-022-01034-6

Vuong, Q. H., \& Napier, N. K. (2014). Making creativity: the value of multiple filters in the innovation process. International Journal of Transitions and Innovation Systems, 3(4), 294327. https://doi.org/10.1504/ijtis.2014.068306 